\title{
DISFARÇA-ME QUE TE DEVORO: YOUTUBERS MIRINS, CONSUMO E SEMIFORMAÇÃO DA CRIANÇA
}

\author{
DISFRÁZAME QUE TE DEVORO: NIÑOS YOUTUBERS, CONSUMO Y SEMI- \\ FORMACIÓN DEL NIÑO
}

\section{DISGUISE ME THAT I DEVOUR YOU: CHILDREN YOUTUBERS, CONSUMPTION AND SEMI-FORMATION OF THE CHILD}

\author{
Aliandra Cristina Mesomo LIRA ${ }^{1}$ \\ Solange Franci Raimundo YAEGASHI ${ }^{2}$ \\ Eliane DOMINICO ${ }^{3}$
}

RESUMO: Este artigo objetiva problematizar o papel e o impacto da indústria cultural na formação das crianças, tomando os youtubers mirins como foco de análise. Para tanto, busca refletir como se configura e atua a indústria cultural, bem como reconhecer as características da cultura digital, as formas de comunicação instituídas pelos youtubers que estimulam o consumo e tecer reflexões sobre como isso impacta na (semi)formação das crianças. É uma reflexão de cunho teórico, a partir de autores fundamentados na teoria crítica e que discutem a infância e sua (re)configuração na contemporaneidade. Como resultados, as novas formas de viver a infância na atualidade têm sido guiadas pelos aparatos tecnológicos como terreno fértil para divulgação de publicidade disfarçada na voz de crianças, moldando seus modos de ser, pensar e consumir.

PALAVRAS-CHAVE: Infância. Consumo. Mídia.

RESUMEN: El artículo tiene como objetivo problematizar el papel y el impacto de la industria cultural en la formación el niño, considerando los niños youtubers como foco de análisis. Para ello, se busca comprender cómo se configura y actúa la industria cultural, así como reconocer las características de la cultura digital, sus formas de comunicación instituidas por los youtubers que estimulan el consumo y hacer reflexiones sobre cómo eso impacta la semiformación de los niños. Se trata de una reflexión de carácter teórico, a partir de autores fundamentados en la teoría crítica, que discuten la infancia y su (re)configuración en la contemporaneidad. De esta forma, llegamos a la conclusión que las nuevas formas de vivir la

${ }^{1}$ Universidade Estadual do Centro-Oeste (UNICENTRO), Guarapuava - PR - Brasil. Docente do Programa de Pós-Graduação em Educação. Doutora em Educação pela Universidade de São Paulo (USP). ORCID: http://orcid.org/0000-0003-2945-464X. Lattes: http://lattes.cnpq.br/1931135933077916. E-mail: aliandralira@gmail.com

${ }^{2}$ Universidade Estadual de Maringá (UEM), Maringá - PR - Brasil. Doutora em Educação pela Universidade Estadual de Campinas (UNICAMP). Docente do Programa de Pós-Graduação em Educação. ORCID: http://orcid.org/0000-0002-7666-7253. Lattes: http://lattes.cnpq.br/5273356754482937 E-mail: solangefry@gmail.com

${ }^{3}$ Universidade Estadual de Maringá (UEM), Maringá - PR - Brasil. Mestre em Educação pela Universidade Estadual do Centro-Oeste (UNICENTRO). Doutoranda em Educação pela Universidade Estadual de Maringá (UEM). ORCID: http://orcid.org/0000-0002-2320-4036. Lattes: http://lattes.cnpq.br/1975198967931634 E-mail: nane_dominico@hotmail.com

RIAEE - Revista Ibero-Americana de Estudos em Educação, Araraquara, v. 14, n. esp. 4, p. 1960-1976, dez., 2019. E-ISSN: $1982-5587$. DOI: https://doi.org/10.21723/riaee.v14iesp.4.12921 
infancia en la actualidad han sido guiadas por los aparatos tecnológicos, configurando terreno fértil para la divulgación de publicidad disfrazada con la voz de un niño que dice para otros niños, moldando, sus modos de ser, pensar y consumir.

PALABRAS CLAVE: Infancia. Consumo. Medios digitales.

ABSTRACT: This article aims to problematize the role and impact of the cultural industry in the training of children, taking the children youtubers as the focus of analysis. In order to do so, it seeks to understand how the cultural industry is configured and operated, as well as to recognize the characteristics of the digital culture, the forms of communication instituted by the youtubers that stimulate consumption and provide reflections on how it impacts on the (semi) formation of children. It is a theoretical reflection, based on authors based on critical theory and discussing childhood and it's (re) configuration in contemporary times. We have come to the conclusion that the new ways of living childhood in the present day have been guided by the technological apparatuses, configuring fertile ground for advertising publicity disguised in the voice of children who speak to other children, thus shaping their ways of being, thinking and consuming.

KEYWORDS: Childhood. Consumption. Media.

\section{Introdução}

Planeta das Gêmeas: 10.599.323. Julia Silva: 4.453.857. Luluca: 5.250.080. Mundo da Vivi: 5.246.004. Isaac do Vine: 6.702.611. Bela Bagunça: 9.461.838. Juliana Baltar: 8.955.419. Canal da Lelê: 4.936.141. Esses são alguns nomes de youtubers mirins brasileiros e número de inscritos em seus canais quando iniciamos a escrita deste artigo. Tratam-se de crianças que usam essa plataforma para entrar em contato com outras crianças, tornando-se fenômenos conhecidos nacional e internacionalmente, configurando uma nova forma de viver a infância na cultura digital das últimas décadas. Com a ajuda e autorização de um adulto, as crianças criam um canal no YouTube e postam vídeos, quase que diariamente, que são vistos por milhares de crianças inscritas. Em poucas horas os vídeos têm centenas de milhares de visualizações e curtidas (likes).

As crianças, no contexto atual, passam muitas horas de seu dia em frente a computadores, ou com tablets e celulares em suas mãos, condição que tem alterado as formas de brincar. Este fenômeno, que não passa desapercebido ou se faz desconhecido pela maioria das crianças da contemporaneidade, modifica a existência, as relações, a configuração da infância e a formação dos sujeitos infantis, instaurando novas formas de governamentabilidade. 
Frente a este cenário, o objetivo deste artigo é problematizar o papel e o impacto da indústria cultural na formação das crianças, tomando os youtubers mirins como foco de análise. Trata-se de reflexão de cunho teórico, a partir de autores fundamentados na teoria crítica e que discutem a infância e sua (re)configuração na contemporaneidade.

Inicialmente apresentamos uma discussão sobre a indústria cultural, seu papel educativo e sua influência na semiformação da criança, especialmente a partir dos estudos de Theodor Adorno e seus precursores. Em seguida, refletimos sobre a relação entre publicidade e consumo e como isso impacta na construção dos desejos das crianças para a posse de um grande número de artefatos culturais. Por último, explicitamos algumas características dos youtubers mirins, suas formas de comunicação e estratégias de adesão, a relação com as indústrias e o consumo e como isso atua na formação das subjetividades infantis.

\section{Indústria cultural, educação e (semi)formação da criança}

O conceito de indústria cultural foi elaborado por Adorno e Horkheimer (1986), que discutem como no contexto histórico de sua hegemonia promove-se o engodo das massas, ou seja, a formação superficial dos sujeitos guiada pela lógica do consumo que promove uma padronização do pensamento, das formas de ser e estar no mundo. A massificação é discutida pelos autores que refletem sobre a relação entre indústria e cultura, lembrando que, muitas vezes, os sujeitos têm consciência de que seus desejos podem ser apenas parcialmente satisfeitos (ou nem mesmo isso) a partir da aquisição dos produtos, mas mesmo assim continuam ilusoriamente a consumir.

A discussão empreendida pelos autores destaca o caráter fetichista dos produtos da indústria cultural e os danos desse no processo formativo da consciência humana, promovendo uma semiformação. A consciência administrada é conduzida por outros, sem espaço para o agir autônomo e refletido, condição que tem atingido especialmente as crianças e moldado suas subjetividades. Segundo Adorno (2010), quando a formação se converte em semiformação temos o espírito alienado, uma forma dominante da consciência atual.

Adorno (2010), ao refletir sobre como a cultura converteu-se em um valor na sociedade, nos ajuda a reconhecer como tem se instaurando o domínio da tecnologia e seus aparatos, que promovem uma formação adaptada, que perpetua a deformidade. A dominação progressiva, diferente em cada época por seu conteúdo e instituições, tem encontrado nos tempos atuais a cultura digital como importante meio para operar suas mudanças. 
Assim, a indústria cultural "[...] leva todos os que riem juntos a se iludirem de terem conseguido a identificação" (ADORNO, 2010, p. 19), difundindo uma pretensa liberdade de escolha que não é possível de existir, pois foi atrofiada na medida em que a espontaneidade se decompõe, definha.

A vida, modelada até suas últimas ramificações pelo princípio da equivalência, esgota-se na reprodução de si mesma, na reiteração do sistema, e suas exigências descarregam-se sobre os indivíduos tão dura e despoticamente, que cada um deles não pode manter-se firme contra elas como condutor de sua própria vida, nem incorporá-las como algo específico da condição humana (ADORNO, 2010, p. 24).

A semiformação adultera a vida sensorial, promovendo uma administração imediata e um espírito conquistado pelo fetiche da mercadoria. Além disso, ela incorre da superficialidade, uma vez que a recepção de informações e imagens deixa de obedecer a critérios imanentes e apoia-se na necessidade construída pela semicultura (ADORNO, 2010).

Nesse processo, as experiências são vividas medianamente e os elementos formativos não assimilados fortalecem o que o autor define como reificação da consciência, ou seja, uma condição de passividade. Uma fixidez, um automatismo, numa relação cega com os produtos culturais que sabotam a capacidade de experiência necessária para a verdadeira formação. A identificação promovida pela indústria cultural incentiva uma relação malsucedida entre sujeitos e produtos (materiais, artísticos, etc.), pois mascara o gosto e promove conformismo, evidenciando a semiformação como consciência alienada (ADORNO, 2010).

Duarte (2003, p. 444), ao refletir acerca do cerne da teoria adorniana sobre semiformação, enfatiza a "[...] ideia de que as camadas desfavorecidas da população, antes que tivessem podido se 'formar' propriamente, tornaram-se facilmente presas do modo atual tecnologicamente mediado - da ideologia, isto é, a indústria cultural”. Nesse sentido, o traço comum entre semiformação e indústria cultural seria o autoritarismo, uma vez que se suprime a possibilidade de liberdade.

Segundo Bandeira e Oliveira (2012, p. 229), a semiformação promove uma falsificação da formação à medida que leva os trabalhadores a

[...] consumir os produtos que a indústria cultural disponibiliza para preencher seu tempo livre, transforma este tempo em um prolongamento do trabalho, excluindo os resquícios de capacidade criativa e, portanto, do exercício das capacidades lúdicas, afetivas e simbólicas que tornam possível o desenvolvimento de um potencial crítico que permita o surgimento de uma práxis transformadora das condições que perpetuam a vida falsa. 
O processo de industrialização, acentuado nas últimas décadas, move a máquina do capitalismo e tem transformado a criança em alvo principal para sustentar o consumo. Cotidianamente, vemos surgir novos produtos, de brinquedos a roupas, de alimentação a material escolar, que invadem as vidas das crianças, via publicidade que constrói desejos de posse, e passam a fazer parte de suas práticas diárias, seja em casa, na televisão, na internet, nas instituições educativas, nos shoppings centers, convencendo-as de que tais objetos são necessários para a inserção na sociedade e para a sua realização pessoal. Como alertam Steinberg e Kincheloe (2004), um conjunto de artefatos culturais que vão de filmes a livros, brinquedos a material escolar e jogos seguem a lógica da mercantilização, mas atuam pedagogicamente.

O consumo desenfreado de tais produtos tenderia a fomentar a disseminação dos pensamentos padronizados, das práticas preconceituosas delirantes e de uma consciência fragmentada praticamente incapaz de relacionar historicamente o passado com o presente, para que se pudesse pensar um futuro diferente (ZUIN; ZUIN, 2017, p. 424).

O caráter fetichista da mercadoria, discutido por Adorno e Horkheimer (1986), produz uma sensação de prazer momentânea, pois os artefatos dirigidos às crianças logo são substituídos ou a eles são agregados outros, necessários para garantir o funcionamento. Tomemos como exemplo a boneca Barbie, difundida especialmente ao público infantil do gênero feminino: nesse caso, não basta ter a Barbie, serão imprescindíveis as roupas da Barbie, o guarda-roupa para guardá-las, o carro para passear, os acessórios, o namorado da Barbie, as amigas da Barbie. Da mesma forma, os carrinhos da Hot Wheels, que estão entre os objetos presentes em grande parte das brincadeiras de meninos, associam-se a pistas, várias delas diferentes em extensão, desafios, loopings. Estes exemplos nos ajudam a compreender que quando a criança consegue a posse da boneca ou dos carrinhos ela tem parcialmente seu desejo atendido, pois logo percebe que lhe faltam outros produtos a eles associados e apresentados como necessários para organizar a brincadeira, o brincar.

Este brincar, construído sobre o ideal do pensamento estereotipado, atua sobremaneira na educação das crianças, ou seja, os objetos lúdicos como artefatos culturais e produto da indústria capitalista propagam, por suas cores, cenários associados e atividades correlacionadas, um condicionamento, que não é totalmente condicionante dada a capacidade de subversão das crianças, mas é bastante conformador nos modos de ser, pensar e agir infantis. Como escreve Adorno (2010, p. 33), a semiformação não permite a experiência formativa baseada na realidade concreta, pois essa “[...] fica substituída por um estado informativo pontual, desconectado, 
intercambiável e efêmero, e que se sabe que ficará borrado no próximo instante por outras informações".

Zuin e Zuin (2017), ao se referirem à concepção de semiformação descrita por Adorno, destacam a hegemonia da indústria cultural na sociedade atual, chamando especial atenção para a dimensão subjetiva de sua atuação. Os autores refletem sobre a necessidade de considerar as mediações históricas nos tempos e espaços em que são produzidas, ou seja, o modo como a semiformação se renova na atual sociedade da cultura digital. Se de acordo com Adorno a formação de uma consciência livre é condição para a autonomia, hoje observamos que o indivíduo é tutelado por outrem, em especial, pela tecnologia, que instaura a cultura digital e opera novas formas de governamentabilidade dos sujeitos, de suas condutas, seus modos de ser e pensar.

Montigneaux (2003) ressalta que, na contemporaneidade, os modelos de consumo têm as crianças como principal alvo, com produtos e serviços específicos para elas. As marcas devem encontrar e promover novas formas de comunicação, a fim de atingir esse público.

Como exemplo, podemos destacar os youtubers, que têm sido patrocinados por grandes conglomerados industriais e também pequenas empresas. Com uma linguagem informal, estes atores privilegiam a dimensão do prazer, do entretenimento, disfarçando os produtos numa vida em frente às telas. Destarte, compreendemos que a cultura digital promove o conhecimento instrumentalizado, da informação fugidia, que escapa entre os dedos, é superficial, e pouco contribuiu para a formação no sentido de promoção da autonomia, da capacidade de pensar. Essa forma de existir encontra acolhida nas crianças deste tempo presente. Como registram Coelho, Costa e Mattar Neto (2018, p. 1078),

Vivenciamos um capítulo importante da história da humanidade: a Era do Digital. Estamos cercados por aparatos tecnológicos (smartphones, tablets, ultrabooks, dentre outros) e imersos em um caldo culturalmente midiatizado (mensagens SMS, e-mails, postagens em redes sociais, dentre outras possibilidades).

Nesse contexto, as crianças compartilham e promovem ações diferentes das que seus pais viveram, pois fazem parte de uma nova geração associada diretamente à tecnologia. Os nativos digitais seriam todos aqueles que cresceram inseridos e cercados pelas tecnologias de informação e comunicação, incluindo-se a geração de youtubers que vemos proliferar na internet (COELHO; COSTA; MATTAR NETO, 2018).

Zuin e Zuin (2017, p. 427) explicam que o vício pelo consumo produzido pelos estímulos visuais promove "[...] modificações profundas tanto na elaboração de representações 
mentais duradouras quanto na percepção sensório-motora que fornece o lastro necessário para o desenvolvimento de tais representações".

Nessa lógica, se tomarmos o caso dos youtubers mirins, o número de vídeos, likes e curtidas nos canais fortalece a lógica de que 'ser' significa 'ser percebido'. Dessa forma, as telas se tornam onipresentes, seja nos contextos familiares, de lazer ou educacionais. As crianças têm deixado de brincar entre si para assistir vídeos de crianças brincando, abrindo embalagens de brinquedos, apresentando suas rotinas, dentre outros.

A universalização da tela feita por meio do computador e suas mais variadas formas - notebooks, tablets, computadores de mesa, entre outras - fomentou a produção de consequências tanto físicas quanto psicológicas que não foram identificadas em toda a sua plenitude, haja vista o fato de que estão sendo ainda vivenciadas. Mas uma delas se destaca diante do fluxo e do consumo contínuos de imagens e sons que se digladiam com o escopo de capturar a atenção de seus consumidores: o vício de consumo dos choques audiovisuais. Se, há alguns anos atrás, as pessoas tinham contato com os choques audiovisuais apenas uma vez por semana, quando frequentavam as salas de cinema, e se tal experiência mudou radicalmente com a massificação da televisão, uma vez que o contato com as telas tornou-se diário, já na sociedade na cultura digital, o consumo de tais choques se torna ininterrupto (ZUIN; ZUIN, 2017, p. 428)

Como registram os autores, não há um descanso nos estímulos, se antes era a televisão, que pouco a pouco foi ocupando cada vez mais o tempo das pessoas, com o computador e, especialmente, os celulares e tablets, essa atenção é disputada ininterruptamente, seja por motivos de trabalho, seja nos momentos de prazer. O impacto das redes sociais nos modos de vida, no tempo dos sujeitos, tem promovido mudanças significativas nos relacionamentos e incidido diretamente inclusive na saúde física e mental dos indivíduos.

\begin{abstract}
A portabilidade dos computadores de bolso - que permitem ao usuário se comunicar on-line por meio do uso das redes sociais, ser localizado e localizar qualquer espaço, acessar quaisquer informações, assistir a vídeos e programas de TV, acessar redes sociais, entre outras funções - faz com que seja insuportável não estar com tal aparelho, o que gera uma sensação de angústia típica do estado dos viciados que são privados de drogas e desenvolvem a síndrome de abstinência (ZUIN; ZUIN, 2017, p. 429).
\end{abstract}

A partir dessas discussões, podemos afirmar que no cotidiano das crianças esse vício é igualmente sentido, por vezes em maior medida, uma vez que com os pais inseridos no mundo do trabalho ficam longos períodos sozinhas. A internet, seja acessada via tablet, celular ou outro dispositivo, captura a atenção das crianças, as educa, atuando sobre sua formação de maneira superficial e fetichizada. 
A concentração é modificada e diminuída, constantemente bombardeada com novos estímulos por meio de produtos que são apresentados como novidade, últimos lançamentos, com mais e mais acessórios do que aqueles que os precederam. Com um jogo rápido de imagens e sons que se sobrepõem, os vídeos postados nos canais do YouTube atraem a atenção dos usuários, em especial, das crianças, que são seduzidas pelas cores, luzes e cenários que apresentam os novos produtos.

Bombardeadas por informações e novidades, em cenários que parecem ser a casa dos youtubers (mas que são muito bem construídos e pensados), as crianças passam a desejar aquela vida, aqueles objetos, como forma de fazer parte deste mundo tão bonito e interessante a seus olhos.

\begin{abstract}
Desse modo, torna-se praticamente insuportável se concentrar por muito tempo na leitura de um determinado texto, pois o corpo e a mente como que imploram pelo acesso contínuo a novas informações audiovisuais, que precisam ser imediatamente consumidas por meio dos links que são constantemente trocados. E é exatamente essa troca constante que faz com que os usuários não consigam ter o tempo necessário para refletir de forma mais aprofundada sobre determinado tópico, o que poderia estimular a produção de representações mentais duradouras e, portanto, de novos conceitos. Eis a forma como a semiformação é revitalizada na sociedade da cultura digital, pois é nesta sociedade, na qual é possível lembrar-se de tudo por meio do acesso ininterrupto de quaisquer informações, que novas formas de esquecimento são engendradas (ZUIN; ZUIN, 2017, p. 431).
\end{abstract}

Embora todo esse jogo produza um efeito de entretenimento, ele acaba por impedir a reflexão sobre o que está sendo visto e ouvido. Ademais, os autores salientam que a capacidade de concentração, tão necessária para a produção de conceitos, "[...] tende a se metamorfosear numa espécie de concentração dispersa, completamente afeita aos novos presentes perpétuos imperdoáveis do atual processo semiformativo" (ZUIN; ZUIN, 2017, p. 434).

Sem sossego e envoltas nessa atmosfera, o consumo entre as crianças é impulsionado sobremaneira pela publicidade.

\title{
Publicidade e consumo: construindo desejos nas crianças
}

Refletir sobre a relação entre infância e consumo na contemporaneidade é uma tarefa tanto complexa quanto necessária e traz consigo uma gama de elementos presentes no cotidiano das crianças que, muitas vezes, são desconsiderados. Complexa, no sentido que exige uma leitura aprofundada das estratégias colocadas em prática pela indústria e pela mídia, reconhecendo que tanto o consumo quanto a infância são campos do exercício do poder. RIAEE - Revista Ibero-Americana de Estudos em Educação, Araraquara, v. 14, n. esp. 4, p. 1960-1976, dez., 2019. E-ISSN: 1982-5587. 
Necessária, porque tem atravessado a infância e sua formação de forma tão contundente que se torna quase impossível escapar da lógica de mercado.

Ao relatar a transição de um arranjo social sólido para um fluído, Bauman (2001) destaca que vivemos em uma conjuntura marcada pela efemeridade, na qual desenvolveu-se mecanismos que disparam estímulos para a aquisição de bens materiais e serviços que se tornam cada vez mais descartáveis.

Essa condição, segundo Castoriadis (2004), tem provocado mudanças sociais, políticas, culturais, epistemológicas e axiológicas, dificultando o desenvolvimento do senso crítico. Assim, configura-se uma sociedade acomodada e inerte, na qual o ser humano perdeu a sua capacidade crítica e interrogativa, tendendo a consumir de forma irrefreada.

De acordo com Momo (2012), a lógica da globalização da mercadoria está sendo transferida para o cotidiano social e tem agenciado tanto adultos quanto crianças. Meninos e meninas são vistos como consumidores em potencial e como força motriz da atividade consumidora no seio familiar.

A cultura contemporânea está repleta dos efeitos da atuação conjunta de empresas e mídia cujo objetivo maior é o estabelecimento e conservação de hábitos de consumo na população. Nesse sentido, Barber (2009) ressalta que existe uma preocupação com um 'etos de infância induzida', que atua sobre as crianças influenciando-as e criando nelas o desejo de consumir. No cerne dessa relação está o capitalismo, que nas últimas décadas tem exercido forte influência sobre essa categoria geracional, tornando esse público um dos alvos de maior interesse do marketing segmentado.

Com a reconfiguração da estrutura familiar no final da idade média, as crianças que antes ficavam sob os cuidados das mães passam a ficar sob a responsabilidade de terceiros e frequentar outros espaços, como as escolas. Nesse contexto, elas foram distanciadas do convívio familiar, gerando culpa nos pais. A pressão e a cobrança pelo pouco tempo vivido com os filhos levaram os pais à tentativa de suprir sua ausência por meio de objetos como roupas, acessórios e brinquedos. A lógica do consumo, com esse objetivo, reestabelece nos adultos a sensação de bem-estar, de compensação, de dever cumprido. O modelo de consumo que há décadas atrás centrava-se no consumidor adulto chegou rapidamente até as crianças, que passaram a ter um lugar importante na família, inclusive orientando escolhas e opinando nas decisões das compras domésticas (SCHOR, 2009).

A expansão do sistema econômico capitalista e a consolidação de sua hegemonia instauraram um processo de colonização da infância, que passou a ser interpelada pela lógica de mercado. Segundo Dornelles (2005), a produção de bens voltados para esse público expandiu RIAEE - Revista Ibero-Americana de Estudos em Educação, Araraquara, v. 14, n. esp. 4, p. 1960-1976, dez., 2019. E-ISSN: 1982-5587. DOI: https://doi.org/10.21723/riaee.v14iesp.4.12921 
largamente a partir da década de 1980, momento no qual a sociedade passou a focar no consumo infantil e a converter as crianças em consumidores. Na lógica do mercado a infância ganha um novo sentido.

A construção do desejo de posse na criança é o resultado do engendramento de um conjunto de saberes produzidos que se implantaram como regimes de verdade. Ciências como a Psicologia, a Medicina e a Pedagogia, dentre outras, passaram a estudar a criança, seu desenvolvimento, seus campos de interesse, sendo seus conhecimentos aproveitados pelas grandes corporações, seja das empresas produtoras de brinquedos, seja pelos conglomerados da mídia e indústria do entretenimento. Mídia e empresas passaram a conhecer as crianças e colocar em prática formas de controlá-la, de agir sobre seus gostos, de falar com elas de forma direta e também mediada (DORNELLES, 2005).

O grande número de artefatos dirigidos ao público infantil conquista as crianças, por meio de uma abordagem sedutora que se apoia no lúdico e na diversão. Os apelos publicitários estão presentes em todos os lugares, na escola, nos parques, nos restaurantes, nos shoppings, construindo desejos e movendo a máquina do consumo. Incessantemente, as crianças são interpeladas por propagandas de brinquedos, alimentos, produtos de beleza, acessórios, material escolar, eletrônicos, tudo muito atraente e 'pensado para elas'.

Com o avanço da tecnologia temos a infância online, conectada aos celulares, computadores, tablets, videogames, vivenciando a cultura digital por meio dos games, canais do YouTube e redes sociais. Para Dornelles $(2005$, p. 81), “[...] da cyber-infância fazem parte as pedagogias culturais que concorrem para engendrar as crianças numa variedade de espaços sociais, incluindo e não se limitando ao espaço escolar".

Lira e Nascimento (2015) registram que a sociedade moderna, do controle e da disciplinarização associou entre seus dispositivos os estímulos ao consumo, ampliando os espaços de administração dos sujeitos da escola e da fábrica para os espaços dos shoppings.

Embora o consumo seja um fenômeno disseminado entre todas as classes sociais, Dornelles $(2005$, p. 90) registra que o grupo social no qual a criança está inserida determinará a forma como ela irá consumir:

A pertença de cada criança em diferentes grupos, ou num grupo específico, induz suas ações e comportamentos, inclusive os de consumo. Isto faz, com que a criança se identifique com os grupos nos quais é incluída, por uma política de inclusão. Tal política de inclusão produz os excluídos, o que não significa estar além ou fora da inclusão, mas, sim, pertencer a um outro grupo: o dos excluídos do mercado, do consumo, dos jogos, dos sites, dos quartos informatizados, dos games, etc. 
O consumo das crianças do grupo dos excluídos muitas vezes se faz pelas margens, correndo tanto pelo acesso a produtos pirateados, réplicas de objetos que barateiam o preço, e também pelo olhar, ao admirar o brinquedo desejado nas vitrines de lojas, ao parar para assistir as propagandas em frente aos televisores sempre ligados, ao folhear as revistas inundadas de publicidade, bem como ao observar o brincar de outras crianças.

Por diversos meios a mídia e a publicidade encontram formas e mecanismos para o convencimento, de forma impactante e abrangente às crianças das diferentes classes sociais. As crianças são conquistadas pelas cores, desenhos, movimentos, cenários, pelo conjunto de elementos que a posse dos objetos traria (DORNELLES, 2005).

A indústria cultural busca exercer nas crianças um poder, cujo objetivo é atuar sobre os gostos e preferências, padronizando comportamentos, anulando a participação e formas diferentes de pensamento. Os impactos do consumo têm sido sentidos massivamente nos corpos e mentes infantis, uma vez as propagandas e os aparatos midiáticos buscam “[...] colonizar a consciência das crianças impondo falsas ideologias e inculcando valores materialistas aos quais as crianças parecem especialmente incapazes de resistir" (BUCKINGHAM, 2007, p. 210).

Nesse contexto, o conceito de semiformação proposto por Adorno (2010), encontra bastante morada, pois retira-se dos sujeitos sua capacidade de reflexão. Ao consumir imagens, produtos, ideias impregna-se do espírito do conformismo e alimenta uma consciência alienada.

A publicidade e a mídia, como pedagogias culturais, têm influenciado a formação das crianças. Alana (2016) menciona que os aparatos midiáticos têm atuado intensivamente sobre o desenvolvimento das crianças. Essa atuação tem adultizado a infância ao oferecer atividades não apropriadas para sua faixa etária. Assim, é comum nos dias de hoje crianças envolvidas em rodas de conversas discutindo sobre as roupas e calçados que usam, sobre os produtos que possuem e sobre o desejo por compras futuras.

Schor (2009) enfatiza que esse constante desejo das crianças pelas compras tem contribuído para a depressão, a ansiedade e a baixa autoestima infantil, pois muitas vezes querem determinados produtos, porém não conseguem adquiri-los, ou ainda, convivem com outras crianças que possuem o brinquedo, a roupa e o acessório que elas têm anseios em possuir.

Estudos realizados pela Academia Americana de Pediatria (ALANA, 2016) apontam uma correlação entre a mídia e a publicidade e o aumento de crianças que apresentam problemas comportamentais. Especialistas que prestam serviços nesse espaço ressaltam que esses distúrbios estão associados aos canais televisivos e à internet, que têm depositado sobre as crianças uma gama de produções que estimulam a erotização e a violência. Alana (2016) considera que as imagens de sexualidade apresentadas nos anúncios infantis têm contribuído RIAEE - Revista Ibero-Americana de Estudos em Educação, Araraquara, v. 14, n. esp. 4, p. 1960-1976, dez., 2019. E-ISSN: 1982-5587. DOI: https://doi.org/10.21723/riaee.v14iesp.4.12921 
para um comportamento sexual precoce nas crianças, roubando-lhes energias que poderiam ser empregadas no brincar e no faz de conta.

A indústria alimentar também tem se utilizado de uma explosão de anúncios sobre alimentos desenvolvidos especialmente para conquistar o paladar infantil. Além de oferecerem venda casada, colocando brinquedos como 'brindes', crescem os investimentos nos espaços que aliam alimentação e lazer infantil, com cardápios e espaços kids. Nas prateleiras dos supermercados opções de alimentos pouco nutritivos, mas muito calóricos, estão ao alcance das crianças, com a presença dos personagens de filmes e desenhos animados nas embalagens dos produtos (DOMINICO; LIRA, 2017).

A estratégia mais atual da publicidade tem sido apresentar produtos por meio de outras crianças no YouTube, os chamados youtubers mirins. De maneira disfarçada e naturalizada, são portadores de um discurso que geralmente inclui 'mostrar' aos seguidores e espectadores outras crianças - as novidades em lançamentos, especialmente de brinquedos e material escolar.

\section{Youtubers mirins e a (con)formação da infância}

Montigneaux (2003), ao discutir as marcas, seu discurso e modos de relacionamento, destaca que os personagens de filmes e desenhos animados aproximam as marcas das crianças, facilitando permutas e otimizando performances. Nos últimos anos, esta tarefa tem sido compartilhada com os youtubers mirins, os quais publicam vídeos de conteúdos variados, muitos deles apresentando e divulgando produtos e marcas, de forma indireta e disfarçada, sem regulamentação.

O YouTube é uma plataforma de compartilhamento de filmes e vídeos da empresa Google, hospedando uma grande variedade de materiais, em sua maioria de produção caseira, mas que tem se refinado na sua apresentação cada vez mais. A criação de um canal facilita que os produtores de vídeos acomodem seus materiais em um só lugar, facilitando o acesso por meio de inscrições. Assim, ao acessar um vídeo, logo abaixo já aparece a 'sugestão' para que a pessoa se inscreva no canal, que vai emitir avisos sempre que um vídeo novo for colocado em circulação. Esse é caso dos youtubers mencionados no início desse texto. Como registram Coelho, Costa e Mattar Neto (2018, p. 1081), com “[...] a internet, houve uma transformação nos modos de criação, tanto ética quanto esteticamente".

Além disso, a tecnologia opera novas formas de vigilância e controle de acesso aos indivíduos, pois os sujeitos infantis inscritos nos canais dos youtubers recebem notificações 
sempre que são postados novos vídeos. Os sinais sonoros e visuais chamam a atenção para a tela, instauram uma rede de comunicação contínua e ininterrupta que interpela os sujeitos e orienta seu modo de vida e formas de pensar, de maneira superficializada e semiculta, como alertou Adorno (2010).

São muitas as sensações prazerosas derivadas do consumo incessante de choques audiovisuais que assumem a forma do tiro ótico. Fisiologicamente, as sensações de prazer advindas desse tipo de consumo podem ser observadas nos olhares embasbacados das crianças, que simplesmente param de fazer qualquer coisa caso lhes sejam apresentadas as telas cujas imagens multicoloridas cintilam intensamente, ao mesmo tempo em que mudam numa velocidade estonteante (ZUIN; ZUIN, 2017, p. 428).

A possibilidade de tornar público um conjunto de vídeos cotidianamente coloca essas crianças em lugar privilegiado e disputado pela indústria, que amplia seus canais de publicidade. Podemos dizer que os youtubers mirins são, na atualidade, os mais novos personagens de divulgação das marcas, uma vez que apresentam os produtos, orientam para os logotipos, divulgam novidades, sendo utilizados eficazmente a serviço das empresas. Nesse processo vemos a semiformação explicitada:

O indivíduo semiculto é aquele que demonstra estar sempre bem informado, a par de tudo o que supostamente acontece, porém de uma forma superficial e acrítica, sem nunca conseguir relacionar os fatos entre si de forma a produzir uma opinião crítica sobre os assuntos em questão (BANDEIRA; OLIVEIRA, 2012, p. 230).

Os youtubers mirins, nesse contexto, instituem modismos, evidenciam determinados produtos, enaltecem lançamentos, conformando o brincar, os modos de vestir, os gostos alimentares, ou seja, os modos de ser das crianças na contemporaneidade. Com a capacidade de concentração arrefecida, as imagens e sons ininterruptos invadem as mentes que têm sua capacidade de reflexão crítica sabotada.

Frente à oferta contínua de choques audiovisuais, que conseguem capturar por instantes a atenção dos que os consomem, dificilmente há o tempo necessário para que se reflita sobre o que está sendo consumido, haja vista que novos links 'clamam' para que sejam imediatamente acessados. É nesse contexto que o meio de concentração da atenção produz sua própria decomposição. Pois, assim que é focada num choque audiovisual, a atenção se despedaça na forma de distrações, que se sucedem no ritmo contínuo e alucinante das trocas de imagens e sons (ZUIN; ZUIN, 2017, p. 429).

Na configuração social contemporânea, onde o acesso à internet e aparelhos eletrônicos tem sido uma constante em nosso dia a dia, os youtubers mirins fazem parte da vida das crianças de modo descontrolado, pois 'invadem' suas casas, mudam suas rotinas e conversam com a RIAEE - Revista Ibero-Americana de Estudos em Educação, Araraquara, v. 14, n. esp. 4, p. 1960-1976, dez., 2019. E-ISSN: 1982-5587. DOI: https://doi.org/10.21723/riaee.v14iesp.4.12921 
criança diariamente. Esta, envolvida na beleza e perfeição da vida e do cotidiano apresentado pelos youtubers, prontamente requer a posse dos objetos vistos nas telas, sem refletir se de fato são necessários ou divertidos.

O ritmo alucinante das distrações que continuamente se alternam, na medida em que nossos olhares são atraídos por estímulos audiovisuais expostos por telas omnipresentes, parece estar fazendo com que a própria capacidade de concentração seja radicalmente transformada, de tal modo que a dispersão torna-se parte de sua constituição (ZUIN; ZUIN, 2017, p. 430).

As implicações éticas e legais da publicidade dissimulada precisam ser consideradas, uma vez que há impactos no comportamento dos consumidores mirins, visto como um grupo mais vulnerável segundo as regras da comunicação. Uma vez que os produtos são apresentados sem identificar patrocinadores e a propaganda não é veiculada em espaço editorial próprio, o apelo tem forte impacto sobre o poder decisório do consumidor, podendo a publicidade invisível ser classificada como abusiva e enganosa.

O conteúdo dos vídeos postados nos canais geralmente está associado a um conjunto de produtos, seja de beleza, diversão, escolar, dentre outros. Os youtubers são considerados influenciadores digitais, uma vez que criadores de conteúdos direcionam e formatam modos de ser, vestir, aconselhando seus seguidores e experimentar produtos, serviços, visitar locais, dentre outras indicações (MARÔPO; SAMPAIO; MIRANDA, 2018). Os influenciadores digitais lucram com os vídeos postados ${ }^{4}$, que saem do amadorismo e chegam à profissionalização, em parte fomentada pelo assédio das empresas no interesse de divulgação dos produtos.

As autoras destacam, ainda, como este fenômeno tem (re)definindo as identidades infantis, especialmente de meninas, que vivem uma infância marcada por uma normatividade de gênero. Assim, as mídias em suas variadas configurações funcionam como amplificadoras de conselhos e palavras de ordem; ao mesmo tempo que os youtubers mirins investem em sua celebrização (co)modificam as experiências de outras crianças, ou seja, eles próprios se transformam em marcas. Assim, ser youtuber pode virar uma atividade regular e lucrativa, a partir do emprego de estratégias que alavancam a audiência, com conteúdo específico e narrativa planejada que inclui irreverência e aproximação com o público-alvo.

${ }^{4} \mathrm{O}$ YouTube gera receitas por meio de publicidade, condição que deve ser aceita pelos criadores dos canais e vídeos. O valor é calculado, dentre outros aspectos, a partir do número de visualização, tempo visto, etc. 
Nessa perspectiva, Dalethese (2017) ressalta que ao consumirem imagens e conteúdo dos vídeos as crianças passam a ser, além de usuárias, emissoras e difusoras de imagens e informações, pois assistem, curtem, comentam e compartilham.

Ao utilizar-se de crianças como porta-vozes de seus produtos, as empresas instituem uma publicidade invisível ou disfarçada. Os vídeos, embora pareçam voltados para o entretenimento, carregam consigo mensagens cujo endereçamento a outras crianças acaba por (re)configurar a infância, impactando na constituição das subjetividades infantis (MELO, 2018).

\section{Considerações finais}

A reconfiguração da vivência da infância na contemporaneidade, especialmente por meio da tecnologia, exige que nos debrucemos com mais atenção nos fenômenos que atingem as crianças e incidem sobre a formação de suas identidades.

A atuação dos youtubers mirins merece ser estudada, tendo em vista suas estratégias de contato com o público infantil e, especialmente, em virtude da associação que o conteúdo de seus vídeos e canais fazem com grandes empresas produtoras de artefatos dirigidos às crianças.

Capturados pelos aparelhos eletrônicos e pelos conteúdos transmitidos por eles, as crianças raramente convidam amigos para brincar em suas casas, ou saem para parques, pois sua 'nova forma de brincar' é assistir outros brincando. Essa reconfiguração tanto das relações sociais quanto da formação tem impactos nas subjetividades infantis, pois as crianças estão mais solitárias, embora bombardeadas com chamados nas telas (Fala galera!, Bom dia, pessoal!), mais sedentárias (a tela promove imobilidade) e dependentes destes aparatos.

Apoiadas em Adorno (2010), buscamos fazer a crítica da semiformação tal como se apresenta no contexto da cultura digital. $\mathrm{O}$ autor alertou sobre o poder que a realidade extra pedagógica exerce sobre as pessoas, sobre a impossibilidade de se opor a esse sistema, o que não significa ficar cego às suas implicações. Nesse sentido, é importante assumirmos a posição daqueles que se debruçam a olhar com mais atenção para esses sujeitos, os conteúdos que veiculam e as vivências que proporcionam, no sentido de fazer a crítica na direção de uma formação mais autônoma. A possibilidade de resistência nesse cenário passa pela necessidade de autorreflexão crítica a respeito da semiformação. 


\section{REFERÊNCIAS}

ADORNO, T. W. Teoria da Semiformação. In: PUCCI, B.; ZUIN, A. A. S.; LASTÓRIA, L. A. C. N. (orgs.). Teoria crítica e inconformismo: novas perspectivas de pesquisa. Campinas, SP: Autores Associados, p. 7-40, 2010.

ADORNO, T. W.; HORKHEIMER, M. Dialética do esclarecimento: fragmentos filosóficos. Rio de Janeiro: Jorge Zahar, 1986.

ALANA, I. Crianças sem marcas. Dicas para os pais que vivem em uma cultura de consumo. São Paulo: Alana, 2016.

BANDEIRA, B. S.; OLIVEIRA, A da R. Formação cultural e semiformação: contribuições de Theodor Adorno para pensar a educação hoje. Educação, Porto Alegre, v. 35, n. 2, p. 225 232, maio/ago. 2012.

BARBER, B. R. Consumido: como o mercado corrompe crianças, infantiliza adultos e engole cidadãos. Rio de Janeiro: Record, 2009.

BAUMAN, Z. A modernidade líquida. Rio de Janeiro: Jorge Zahar, 2001.

BUCKINGHAM, D. Crescer na era das mídias eletrônicas. São Paulo: Loyola, 2007.

CASTORIADIS, C. Encruzilhadas do labirinto VI: figuras do pensável. Rio de Janeiro: Paz \& Terra, 2004.

COELHO, P. M. F.; COSTA, M. R. M.; MATTAR NETO, J. A. Saber digital e suas urgências: reflexões sobre imigrantes e nativos digitais. Educação \& Realidade, Porto Alegre, v. 43, n. 3, p. 1077-1094, jul./set. 2018.

DALETHESE, T. R. Faz de conta que todos nós somos youtubers: crianças e narrativas contemporâneas. Dissertação de Mestrado, 173f. Universidade Federal do Rio de Janeiro, Rio de Janeiro, 2017.

DOMINICO, E.; LIRA, A. C. M. De princesas a super-heróis: a influência dos personagens na alimentação e educação das crianças. Rev. Fac. Educ., Mato Grosso, v. 28, n. 2, p. 113 127, jul./dez. 2017.

DORNELLES, L. V. Infância que nos escapam: da criança na rua à criança cyber. Petrópolis: Vozes, 2005.

DUARTE, R. Esquematismo e Semiformação. Educ. Soc., Campinas, v. 24, n. 83, p. 441457, ago. 2003.

LIRA, A. C. M.; NASCIMENTO, E. C. M. Infância e cultura. Curitiba: CRV, 2015.

MARÔPO, L.; SAMPAIO, I. V.; MIRANDA, N. P de. Meninas no YouTube: participação, celebrização e cultura do consumo. Estudos em Comunicação, Covilhã, Portugal, n. 26, v. 1, p. 175-195, maio 2018. 
MELO, D. R. de. Infância youtuber: um estudo sobre modos de ser criança na contemporaneidade. Dissertação de Mestrado, 146f. Universidade Luterana do Brasil, Canoas, 2018 .

MOMO, M. Mídia, consumo e os desafios de educar uma infância pós-moderna. In: DORNELLES, L. V.; BUJES, M. I. E. (Org.). Educação e infância na era da informação. Porto Alegre: Mediação, p. 29-49, 2012.

MONTIGNEAUX, N. Público-alvo: crianças - a força dos personagens e do marketing para falar com o consumidor infantil. Rio de Janeiro: Campus, 2003.

SCHOR, J. Nascidos para comprar: uma leitura essencial para orientarmos nossas crianças na era do consumismo. São Paulo: Gente, 2009.

STEINBERG, S. R.; KINCHELOE, J. L. Sem segredos: cultura infantil, saturação de informação e infância pós-moderna. In: STEINBERG, S. R.; KINCHELOE, J. L. Cultura infantil: a construção corporativa da infância. 2. ed. Rio de Janeiro: Civilização Brasileira, p. 9-52, 2004.

ZUIN, V. G.; ZUIN, A. A. S. A atualidade do conceito de semiformação e o renascimento da Bildung. Espaço Pedagógico, Passo Fundo, v. 24, n. 3, p. 420-436, set./dez. 2017.

\section{Como referenciar este artigo}

LIRA, A. C. M.; YAEGASHI, S. F. R.; DOMINICO, E. Disfarça-me que te devoro: youtubers mirins, consumo e semiformação da criança. Revista Ibero-Americana de Estudos em Educação, Araraquara, v. 14, n. esp. 4, p. 1960-1976, dez., 2019. E-ISSN: 1982-5587. DOI: https://doi.org/10.21723/riaee.v14iesp.4.12921

Data de submissão: $25 / 06 / 2019$

Data de aceite: 21/07/2019

Data de publicação: 01/09/2019 